\section{Perfect swan song}

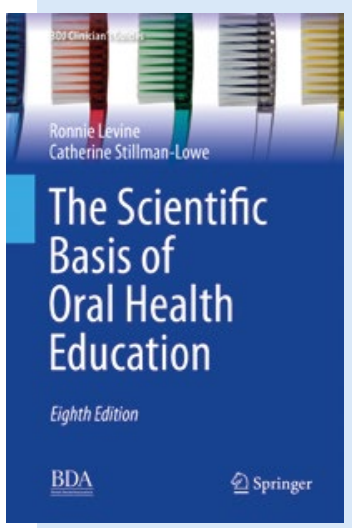

The Eighth Edition of The Scientific Basis of Oral Health Education has just been published by the BDA. It is designed for all Dental Care Professionals, and will be especially valuable for those training the next generation of recruits, as well

as current practitioners wishing to update their knowledge. For the first time it is available as an e-book.

The first edition of The Scientific Basis of Dental Health Education appeared in 1976 and was a slim booklet with a green cover. It arose from a joint attempt by the British Association for the Study of Community Dentistry and the UK Health Education Council, who published it, to refine and standardise the advice given to the public and to ensure that such advice was scientifically sound. Over the following
40 years, the booklet eventually grew into a book, and found an independent publisher, BDJ Books. It was at this point that Cathy Stillman-Lowe and Dr Ronnie Levine OBE took on the editing.

Cathy said: 'I am absolutely delighted that my co-author, Dr Ronnie Levine, and myself, have brought to fruition an eighth edition of this trusted book. This time, we have of course updated all the evidence, but we have also orientated the book for an international audience, so that it can be used more widely'.

'As I am retiring now, this eighth edition will be my swan-song. I want to thank Dr Levine for his incredible diligence and expertise, over so many editions, and also my late husband, Michael, who sadly died from oral cancer in 2017, and whose loving care enabled me to work in a role that gave me huge satisfaction.'

Levine R, Stillman-Lowe C. The Scientific Basis of Oral Health Education - 8th Edition. London: Springer Nature, 2018. Available to buy at the BDA shop https://shop.bda.org/ where BDA members are entitled to a $20 \%$ discount.

\title{
Essential administrator's guide
}

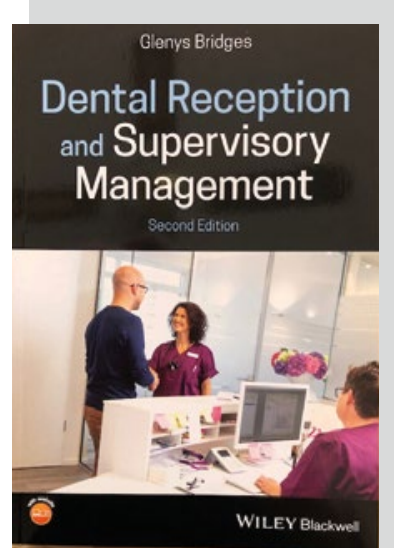

Dental Reception and Practice Management 2nd Edition by Glenys Bridges is the dental administrator's essential companion to all aspects of reception work and supervisory

practice management duties. It's designed for use by dental receptionists in practice and will also greatly benefit dental nurses, dental hygienists, and dentists.

The book covers vital interpersonal skills and the essential aspects of business management and marketing relevant to dentistry. It explains the development of dental care, enhancing the reader's understanding and awareness of the necessary clinical aspects of dentistry.

It also addresses the General Dental Council's Standards for the Dental Team, which details the nine principals for observing patient rights, and looks at new regulations introduced by the Health and Social Care Act.

- Provides practical advice for dental receptionists wishing to upgrade their skills

- Covers all aspects of the receptionist role, from administration and marketing to quality management and patient experience

- Looks at new standards and regulations put into effect

- Offers concrete suggestions for customer care and business development

- Includes access to a companion website with activities and links to useful websites

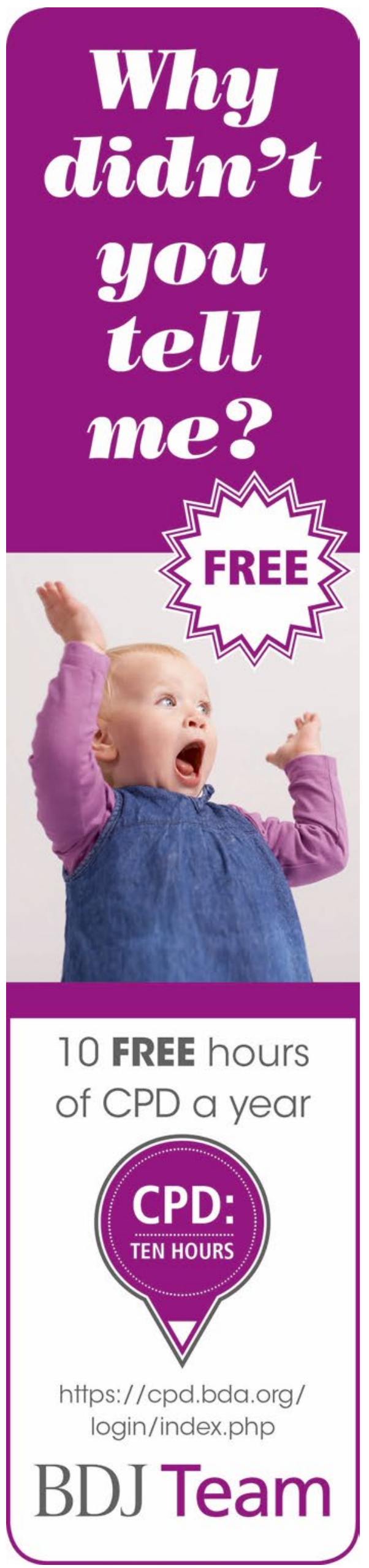

